\title{
Seasonal changes of testicular parameters in southern pudu Pudu puda in relationship to circannual variation of its reproductive hormones
}

\author{
Eugenia REYES, George A. BUBENIK*, Dieter SCHAMS, \\ Alejandro LOBOS and Rosa ENRIQUEZ
}

\begin{abstract}
Reyes E., Bubenik G. A., Schams D., Lobos A. and Enriquez R. 1997. Seasonal changes of testicular parameters in southern pudu Pudu puda in relationship to circannual variation of its reproductive hormones. Acta Theriologica 42: 25-35.

Seasonal variation of testicular and epididymal parameters in the smallest deer, the southern pudu Pudu puda Molina, 1782 were related to the circannual fluctuation of plasma levels of its reproductive hormones. The diameter and the length of testes, the diameter of epididymis as well as the diameter and the heights of epithelium of seminiferous and epididymal tubules were measured. Morphological evaluation of spermatogenesis were performed on histological sections of testicular and epididymal tissues. Most of these gonadal parameters exhibit a seasonal variation which is in accordance with the reproductive pattern as well as the variation of reproductive hormones. Seasonal fluctuations of $\mathrm{LH}$ and testosterone indicate two seasonal activations of the reproductive system, one in the spring (antler mineralization), the other in the fall (rut). FSH exhibit one prolonged peak (summer to fall) whereas prolactin follows the expected, photoperiodically-dependant time course with peak levels around the summer solstice. The measurements of testicular parameters indicate a prolonged period of gonadal activity in southern pudu but the period of maximal reproductive stimulation is limited to the time around the rut.

Department of Molecular Biology, Universidad de Concepcion, Concepcion, Chile (ER, AL, RE); Department of Zoology, University of Guelph, 50 Stone Rd.-E., Guelph, Ontario, Canada, N1G 2W1, Phone: (519) 824 4120, Ext.8786, e-mail: gbubenik@uoguelph.ca (GAB); Department of Physiology, FML, Technical University of Munchen-Weihenstephan, D-85350 Freising, Germany (DS)

Key words: Pudu, testes, epididymis, seasonality, morphology, reproductive hormones
\end{abstract}

\section{Introduction}

In wild ungulates of temperate zones, photoperiodicity regulates the important life-sustainable activities such as feeding, locomotion, sleep and reproduction. Cervid species inhabiting temperate zones are seasonal breeders and therefore their reproductive organs and concentrations of reproductive hormones exhibit annual changes which are synchronized by light. In male cervids, these changes were studied in red deer Cervus elaphus (Jaczewski 1954, Lincoln 1971, Hocherau-de

\footnotetext{
*to whom the correspondence should be sent
} 
Riviers and Lincoln 1978), fallow deer Dama dama (Chaplin and White 1972, Rolf and Fischer 1990), roe deer Capreolus capreolus (Stieve 1949, Bubenik 1971, Schams and Barth 1982, Sempere 1990), sika deer Cervus nippon (Suzuki et al. 1992), wapiti Cervus elaphus canadensis (Haigh et al. 1984), white-tailed deer Odocoileus virginianus (Wislocki et al. 1947, Mirarchi et al. 1977, 1978) and several other species.

Circannual changes of reproductive hormones were also investigated in males of subtropical and tropical deer, such as Rusa deer Cervus rusa timorensis (van Mourik and Stelmasiak 1990), axis deer Axis axis (Loudon and Curlewis 1988, Bubenik et al. 1991), muntjac Muntiacus reevesi (Chapman and Harris 1991) and Eld's deer Cervus eldi thamin (Monfort et al. 1993). Most recently, our group determined the rate of development of reproductive organs and circannual variation of luteinizing hormone (LH), follicle stimulating hormone (FSH), testosterone (T), and prolactin (PRL) in plasma of male southern pudu Pudu puda Molina, 1782, a small subtropical deer living in Chile (Reyes et al. 1988, Reyes-Toledo et al. 1993, Bubenik et al. 1996).

In most of the previously mentioned cervid species, the testicular volume, the size of epididymis and the amount of spermatozoa in the seminiferous tubules and the epididymal canals were undergoing distinct seasonal changes which more or less correspond to circannual variation of levels of reproductive hormones (Lincoln 1971, Mirarchi et al. 1977, 1978, Haigh 1984, Sempere 1990, Monfort et al. 1993). In pudu, however, we have detected one seasonal elevation for prolactin and FSH, but two other hormones, $\mathrm{LH}$ and $\mathrm{T}$ exhibited two peaks of almost equal size, one of them in the spring and the other in the fall. What is mostly remarkable, the pudu exhibit only one fall rut followed by a parturition period after approximately 203 days of pregnancy (Reyes et al. 1988).

In order to elucidate this obvious discrepancy between the seasonal variation of reproductive hormones and the reproductive pattern of this species, we measured the size of testes and the epididymis, the diameters of their lumens as well as the thickness of the epithelial cells during the four seasonal periods and compared them with the circannual variation of reproductive hormones.

\section{Material and methods}

The studies were carried out during approximately one year period at the animal care facility of University of Concepcion, Chile. The measurements were performed in six adult males which were immobilized by 1:1 mixture of Rompun (xylazine hydrocholoride) and Ketamine (ketamine hydrochloride) delivered by an injection dart. The details of this technique are described in our previous publication (Bubenik and Reyes-Toledo 1994). The measurements of testes and epididymides (length and diameter) were performed by caliper on immobilized deer. The diameter of each caput epididymis was calculated by subtracting the values of testes length without epididymis from the values of testis length with the epididymis. Tissue samples were obtained either from animals which were sacrificed because of injuries or from healthy males in which a needle biopsy was performed. Tissue samples from the testes were available only from January $(n=6)$, March $(n=6)$, August $(n=6)$, September 
$(n=6)$ and November $(n=6)$ and the tissue samples from the epididymis were available only from March $(n=6)$, August $(n=6)$ and September $(n=6)$. The measurements of testes and epididymis were performed in January, March, July, September, October and November,

The gonadal tissues were fixed in Bouin solution, embedded in paraffin, section to $20 \mu$ and then stained with hematoxylin and eosin. The diameter of seminiferous tubules and the epididymal tubules as well as the thickness of epithelial cells of the seminiferous tubules and the ductus epididymis were measured by an ocular micrometer in 10-12 sections magnified 125 or 200 times.

Blood samples were taken from the jugular vein into pre-heparinized tubes and after centrifugation, the plasma was frozen to $-20^{\circ} \mathrm{C}$ until further radioimmunoassays (RIA) for the reproductive hormones was performed. The details of these techniques were reported in Bubenik et al. (1996).

The data of testicular parameters were subjected to a multiple range analysis of variance (ANOVA) using Quattropro software, and the Mann-Whitney $U$-test. Significant differences were expressed at the $95 \%$ confidence level. The data on seasonal changes in plasma concentration of hormones were subjected to General Linear Model Procedure for Unbalance ANOVA (SAS) and the differences between means were determined by $t$-test. Because no significant differences in testicular parameters were detected between the right and the left testes, both measurements were combined.

\section{Results}

The largest average value of the testicular length $(32.4 \mathrm{~mm})$ was observed in March (rut) but only slightly smaller value $(31.3 \mathrm{~mm}$ ) were found in November or January (31.1 mm) (Fig. 1). The smallest average lengths were detected in July (winter; $24.7 \mathrm{~mm}$ ) and September $(26.2 \mathrm{~mm}$ ). Statistical calculation showed no significant differences between November and March (late spring, early fall) and between July and October (winter and spring). However, a significant increase $(p<0.05)$ was detected in November as compared to October.

Testicular diameter peaks in January and March (both months $21.8 \mathrm{~mm}$ ) and the minimal value ( $14.8 \mathrm{~mm}$ ) was found in July (Fig. 1). There were no significant differences between July, September and October but a significant increase $(p<0.05)$ occured between October and November as well as between November and January.

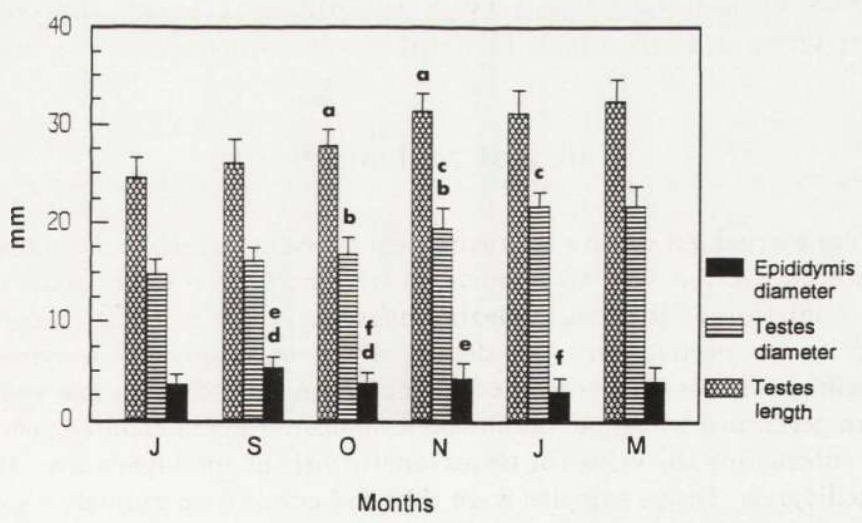

Fig. 1. Seasonal variation of length and diameter of testes and the diameter of epididymis in pudu $(n=6)$. Values marked with the same letter are significantly different $(p<0.05)$. 
The variation of average diameter of epididymis exhibited only a minimal seasonal variation with highest values $(5.4 \mathrm{~mm})$ observed in September (spring) and lowest value $(2.8 \mathrm{~mm}$ ) detected in January (summer; Fig. 1). A significantly higher levels $(p<0.05)$ were detected in September as compared to October. September values were also higher than those of November and October levels were higher than January values.

A pronounced seasonal variation in diameters of seminiferous tubules (S.T.) was detected (Fig. 2 ) with peak values $(36.9 \mu)$ observed in March (rut) and the lowest values $(19.0 \mu)$ detected in September. The largest variance in lumen diameter (ranging from 17.7 to 63.0) was observed in March. The values for both months, January and March differed significantly $(p<0.05)$ from August and September values, and September differed from November.

The seasonal variation of epithelial height of S.T. followed closely the pattern established for the diameter of S.T. (Fig. 2). Peak values (10.7 $\mu$ ) were observed in March and the lowest values (3.7) were detected in September. Significant differences $(p<0.05)$ were detected between January and September, March and August, March and September, and also between November and January.

The highest value of the diameter of the epididymis $(30.8 \mu)$ was obtained from March and the lowest $(14.6 \mu)$ was observed in September (Fig. 2). The March value differed significantly $(p<0.05)$ from the values in August and September.

The epithelial height exhibited the lowest value $(2.3 \mu)$ in August and the highest $(6.7 \mu)$ in March (Fig. 2). The March values were significantly different $(p<0.05)$ from values in August. A fully developed seminiferous tubules with

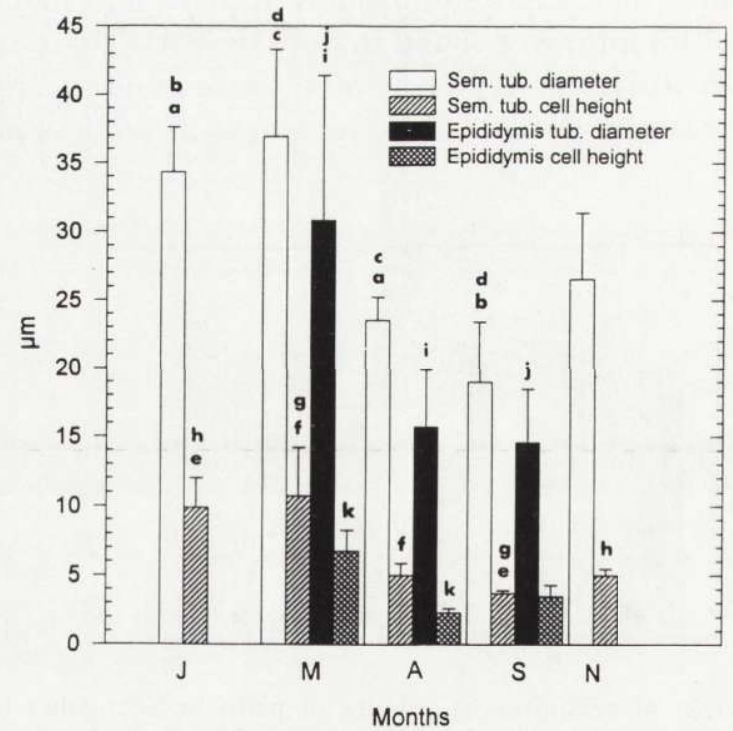

Fig. 2. Seasonal variation of diameter and epithelial height of seminiferous and epididymal tubules in pudu $(n=6)$. Values marked with the same letter are significantly different $(p<0.05)$. 


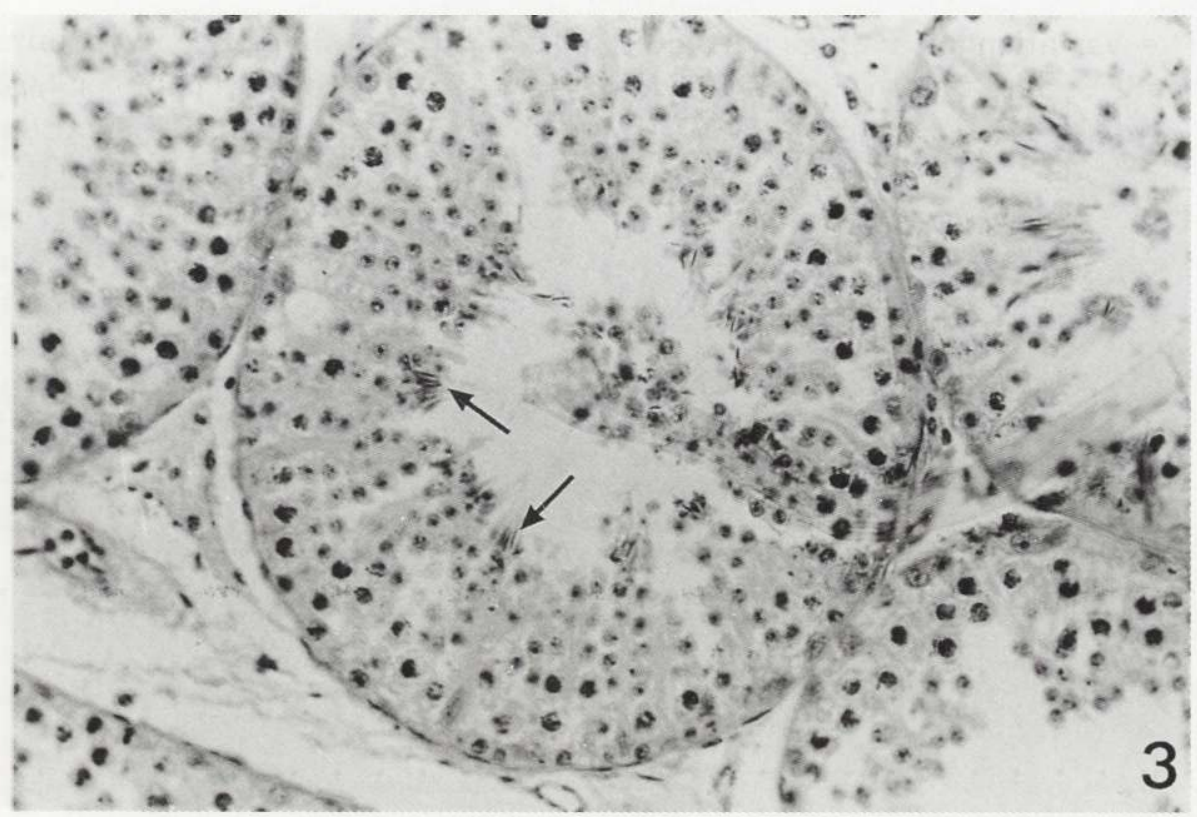

Fig. 3 Transverse section of seminiferous tubules of pudu in March (rut). Note the wide thickness of the germinative epithelium and the presence of mature spermatozoa in the central canal. Magnification $200 \times$

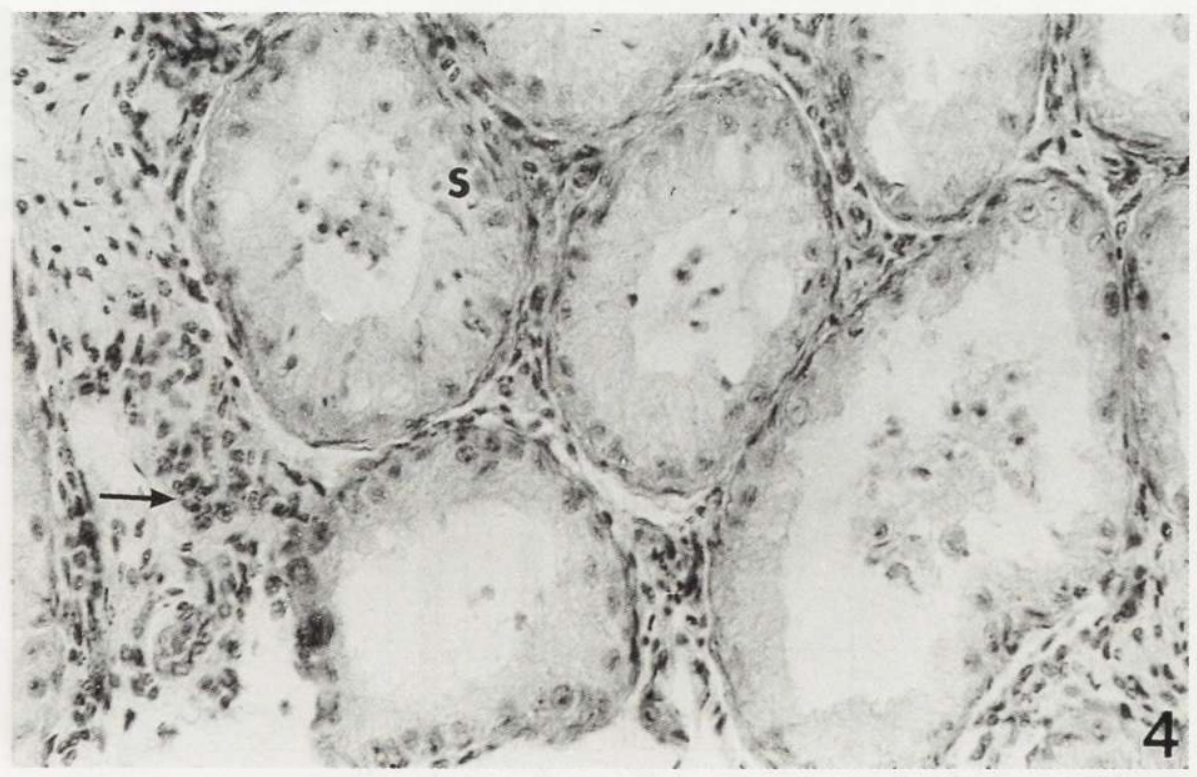

Fig. 4. Transverse section of seminiferous tubules of pudu in September (spring). Note the thin germinative epithelium consisting mostly from spermatogonia and the few undifferentiated cells seen in the lumen. Compare the large size of the interstitial tissues in this section containing numerous Leydig cells with the much smaller number of these cells seen in the Fig. 3. Magnification 125x. 


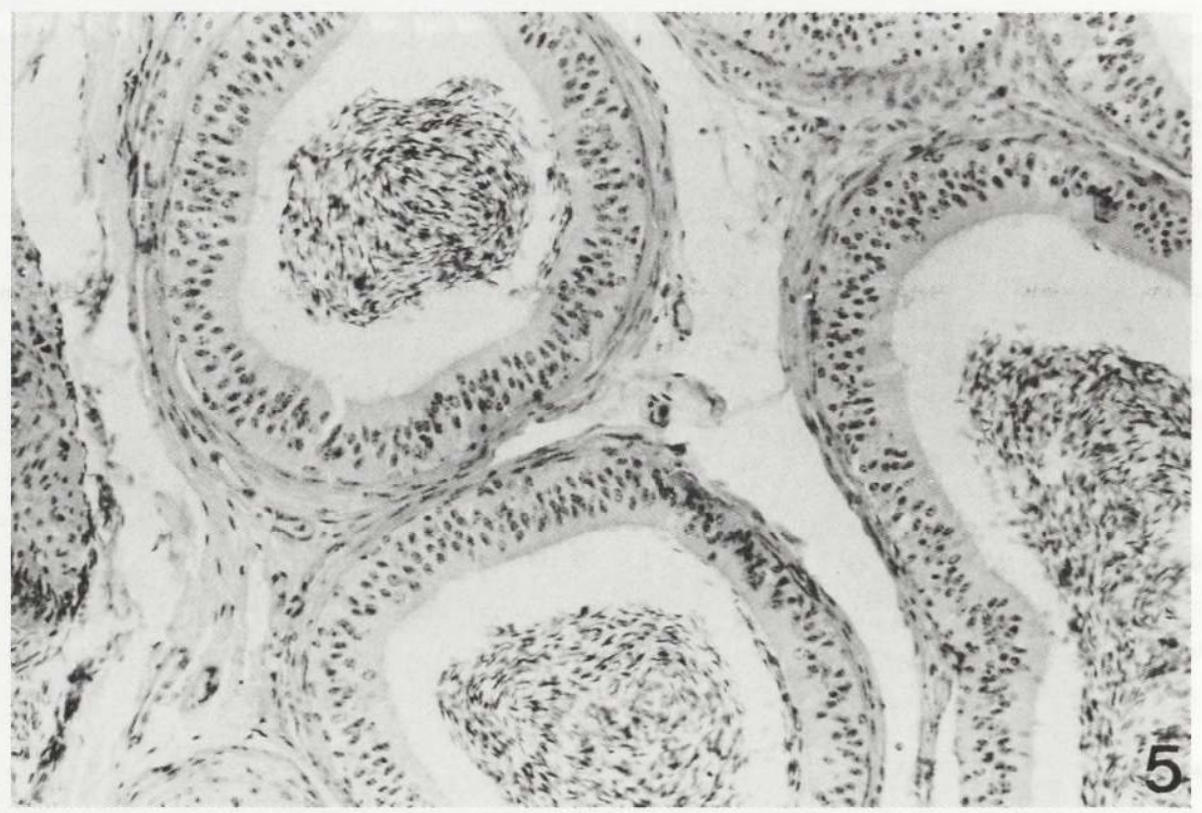

Fig. 5. Transverse section of the epididymal tubules of pudu in March. Note the thick epithelium of the tubular walls and the large lumens filled with great quantity of spermatozoa. Magnification 125x.

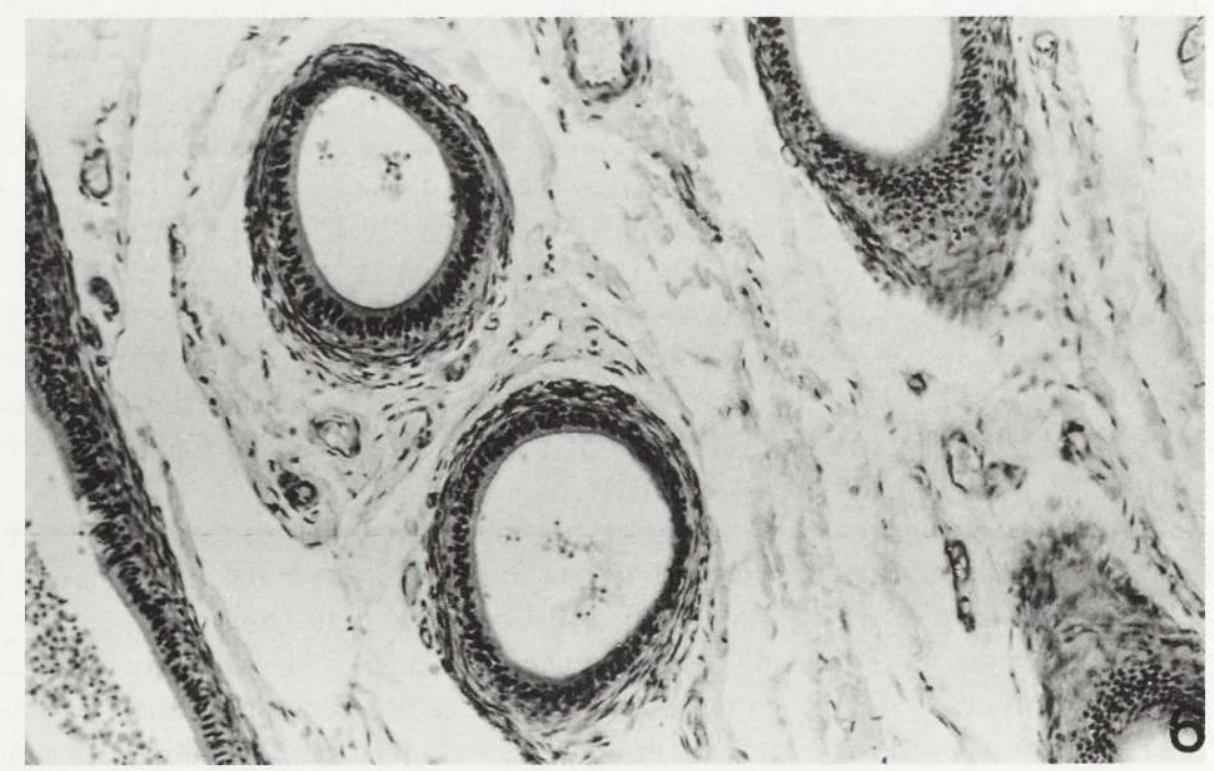

Fig. 6. Transverse section of the epididymal tubules of pudu in September. Note the thin tubular wall and the mostly empty lumen containing occasionally few spermatocytes. Note also the massive amount of intertubular connective tissue in this section as compared to Fig. 5. Magnification 125x. 
mature spermatozoa present in the lumen and large interstitial spaces with well developed Leydig cells were observed in March (Fig. 3). In September mostly only spermatogonia were visible inside the seminiferous tubules but paradoxically, large interstitial spaces were filled with densely compacted Leydig cells (Fig. 4).

An enlarged epididymal tubules filled with numerous, closely compacted spermatozoa, were observed in March (Fig. 5). In September, the tubules were wide open and only infrequently few precursor cells (most probably spermatocytes) were encountered inside the lumen (Fig. 6).

Average values of LH exhibited two peaks $(p<0.05)$, one in August (winter) $(1.78 \mathrm{ng} / \mathrm{ml})$, the other in March (fall) $(1.90 \mathrm{ng} / \mathrm{ml})$. The levels of testosterone showed also two peaks of almost equal size $(p<0.001)$, one in March $(3.18 \mathrm{ng} / \mathrm{ml})$, the other in October $(3.11 \mathrm{ng} / \mathrm{ml})$. FSH levels exhibited a prolonged peak period from December (summer) $(58 \mathrm{ng} / \mathrm{ml})$ to March $(63 \mathrm{ng} / \mathrm{ml})(p<0.01)$. Finally, average prolactin (PRL) concentration reached peak values $(28.3 \mathrm{ng} / \mathrm{ml})$ in December (summer solstice) $(p<0.001)$ and the lowest one $(2.8 \mathrm{ng} / \mathrm{ml})$ in April (fall). The two seasonal peaks of LH and T, as well as the single peaks of FSH and PRL were significantly higher than the minimal values of the year (Fig. 7).

\section{Discussion}

Most cervids living in the boreal or temperate regions are strongly influenced by a photoperiod and exhibit a clearly-defined rutting period, restricted to only few weeks (Goss 1969, Lincoln 1985). Conversely, there is a general rule that the populations living closer to equator exhibit a longer rutting season than populations found in the more boreal regions (Zuckerman 1953, Bubenik et al. 1990). The northern limit of southern pudu's distribution $\left(35^{\circ} \mathrm{S}\right.$; Hershkowitz 1982 ) would suggest that this species could accommodate an extended rutting period. This indeed was the case of the reproductive pattern of captive pudu bred in Cologne Zoo in Germany. Although 55\% of fawns were born in May (spring) and another $15 \%$ were born in June, the rest of fawns were born in July, August, September, January, and April (Hershkovitz 1982). A similar pattern of parturition was also observed in the breeding captive colony kept at the University of Concepcion in Chile (Reyes et al. 1988).

The seasonal parameters of reproductive hormones in southern pudu indicates a bi-seasonal activation of the reproductive axis (Reyes-Toledo et al. 1993, Bubenik et al. 1996) with equal peak levels of $\mathrm{LH}$ and $\mathrm{T}$ observed in the spring and the fall. In addition, an extended period of high concentration of FSH was also detected (see Fig. 7). A temporary spring elevations of reproductive hormones is not unique to pudu as it was observed in several other cervid species (Bubenik 1986). However, these out of rut peaks do not come close to the rutting values, as was the case in pudu (Fig. 7). The only exception is the roe deer, where a regular bi-annual elevation of testosterone was reported (Schams and Barth 1982, Sempere 1990). 


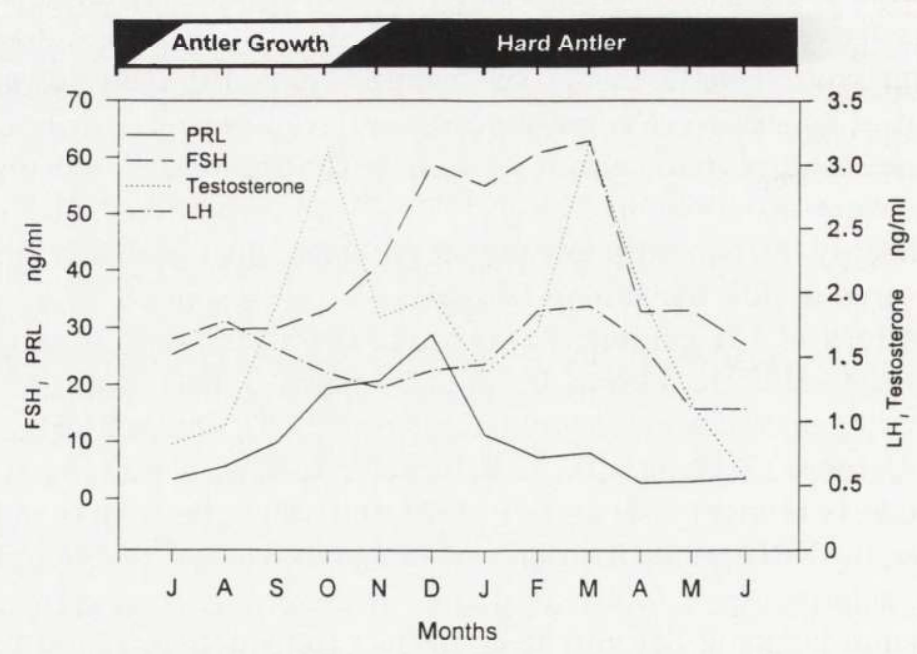

Fig. 7. Circannual variation of $\mathrm{LH}$, testosterone, FSH, and prolactin in southern pudu. Note the close correspondence of bi-annual elevation of LH and testosterone $(n=6)$.

Whereas some testicular parameters in pudu, such as the diameter of seminiferous and epididymal tubules (Fig. 2), exhibit well pronounced seasonal variation, other parameters, such as the length and diameter of testes (Fig. 1) reflect an extensive (several months long) period of reproductive activation. In addition, the histological picture of testes and epididymides indicate a maximal reproductive activation around the rut. On the contrary, the seasonal variation, in testis length and the diameter, is minimal and the diameter of the epididymis is wider in September than during the rut in March (Fig. 1). This discrepancy of seasonal variation was also noticed in the testicular morphology. It is interesting to note, that the rather remarkably enlarged testicular interstitia observed during the month of September follows the preceding elevation of LH, seen in August (Fig. 7). In addition, the subsequent elevation of T levels (peaking in October) may have maintained the activation of the reproduction, as evidenced by the 5 month-long elevation of FSH (Fig. 7). In that respect, the pudu appears to be somewhat similar to roe deer (Schams and Barth 1982). Because of the restricted time available to reactivate the reproductive axis after the winter lull, the LH rises in the spring, followed by testosterone and FSH. The rising LH levels activate the Leydig cells and induce the increase of testes size. Similarly to roe deer, the first $\mathrm{T}$ peak, observed in pudu in October causes the antler mineralization; the second $\mathrm{T}$ peak (in March) coincides with the rut (Fig. 7) (Sempere 1990). (It should be pointed out that October in the southern hemisphere corresponds to April in the northern hemisphere; March corresponds to September). The role of FSH appears to be limited to the activation and maintenance of spermatogenesis. The distinct sea- 
sonal variation of prolactin, which follows the circannual variation of day-length indicated that pudu's reproduction is photoperiodically-controlled (Bubenik 1986).

The discrepancy between the usually sharp circannual peak of testosterone and the limited period of the rutting behaviour (only few weeks) and the prolonged period of fertility reported in most male cervids (lasting up to 6 months) is not restricted to temperate or tropical deer. Such extended period of male fertility was reported not only in the tropical Eld's deer (Monfort et al. 1993) and Reeve's muntjac (Chapman and Harris 1991), temperate axis deer (Loudon and Curlewis 1988) and the atypically breeding cervids such as the roe deer (Stieve 1949), but was also observed in the typically short-day breeding cervids, such as the red deer (Lincoln 1971, Bubenik et al. 1985), wapiti (Haigh et al. 1984), white-tailed deer (Mirarchi et al. 1977), and sika deer (Suzuki et al. 1992).

In his review of seasonal breeding of deer Lincoln (1985) suggested, that a circannual decrease in testis weight of at least $75 \%$ is necessary to assure a complete cessation of spermatogenesis. This hypothesis is supported by data from several boreal cervids in which there is a concise seasonal rut followed by a limited parturition period. In fallow deer, the maximal seasonal decline of testicular weight was around $85 \%$ (Chaplin and White 1972), in roe deer the testicular volume decreased by $84 \%$ (Stieve 1949) and in white-tailed deer and red deer the testes weight declined by $76 \%$ (Mirarchi et al. 1977) and 75\%, respectively (Lincoln 1971). In the tropical Eld's deer however, the scrotal circumference declined seasonally by $50 \%$ (Monfort et al. 1993), but the temperate sika deer, the testes size decreased by only 36\% (Suzuki et al. 1992). The smallest decline of testicular size were then observed in the tropical axis deer (27\%), (Loudon and Curlewis 1988), temperate pudu (24\%) (this study) and the tropical Reeve's muntjac (23\%) (Chapman and Harris 1991). Interestingly, these cervids with low seasonal variation of testicular size differ in their reproductive and antler cycle patterns. Whereas axis deer exhibit no interindividual seasonal synchronization of the antler or the reproductive cycle (Loudon and Curlewis 1988), in muntjacs only the antler cycle is seasonally synchronized but not the reproduction (Chapman and Harris 1991). In pudu, both the antler cycle and the reproductive pattern are more or less synchronized (Reyes et al. 1988, Bubenik et al. 1996).

In view of these facts, the seasonal pattern of testicular activation and the circannual variation of reproductive hormones, as described here in pudu, is not entirely surprising. As the ancestral pudu originated in the subequatorial regions of South America (Hershkovitz 1982) it can be speculated that its original reproductive pattern was aseasonal. Only when the southern pudu move to his current location, his rut and the parturition period stabilized in the most optimal periods of the year.

Our data provides the first evidence, that seasonal changes of testicular parameters in southern pudu are corresponding to the circannual variation of its reproductive hormones. We have concluded, that the reproductive system of male 
pudu exhibits a prolonged period of gonadal activation but the maximal stimulation is clearly limited to the time around the rut.

Acknowledgements: The authors would like to acknowledge the exemplary care of animals by Mr D. Salvador de Silva, the skillful preparation of graphs by Mr G. Humphreys, the statistical help by Dr L. Bartos and the clerical assistance of Mrs. Y. Imai.

\section{References}

Bubenik G. A. 1971. Neuroendokrine Tätigkeit des Hypothalamus des Rehbockes im Laufe des Geweihzyklus. (Neuroendocrine activity in the hypothalamus of the roe buck in relation to its antler cycle). 10th Congress of International Union of Game Biologists, Paris: 651-665.

Bubenik G. A. 1986. Regulation of seasonal endocrine rhythms in male boreal cervids. [In: Endocrine rhythms as adaptive mechanisms to the environment. I. Assenmacher and J. Boissin, eds]. International Colloqium Centre Nationale de Recherche Scientifique, Centre d'Etudes Biologique des Animaux Savauges, Foret de Chize, France: 461-474.

Bubenik G. A. and Reyes-Toledo E. 1994. Plasma levels of cortisol, testosterone and growth hormone in pudu (Pudu puda Molina) after ACTH administration. Comparative Biochemistry and Physiology 107A: 523-527.

Bubenik G. A., Bubenik A. B. and Frank A. 1985. Aussersaisonale Brunft beim Edelhirsch (Cervus elaphus maral). Zeitschrift für Jagdwissenschaft 21: 129-133.

Bubenik G. A., Brown R. D. and Schams D. 1990. The effect of latitude on the seasonal pattern of reproductive hormones in the male white-tailed deer. Comparative Biochemistry and Physiology 97A: $253-257$.

Bubenik G. A., Brown R. D. and Schams D. 1991. Antler cycle and endocrine parameters in male axis deer (Axis axis): Seasonal levels of LH, FSH, testosterone, and prolactin and results of GnRH and ACTH challenge tests. Comparative Biochemistry and Physiology 99A: 645-650.

Bubenik G. A., Reyes E., Schams D., Lobos A. and Bartos L. 1996. Seasonal levels of LH, FSH, testosterone and prolactin in adult male pudu (Pudu puda). Comparative Biochemistry and Physiology 15 B: 417-420.

Chaplin R. E. and White R. W. G. 1972. The influence of age and season on the activity of the testes and epididymides of the fallow deer. Journal of Reproduction and Fertility 30: 361-369.

Chapman N. and Harris S. 1991. Evidence that the seasonal antler cycle of adult Reeves' muntjac (Muntiacus reevesi) is not associated with the reproductive quiescence. Journal of Reproduction and Fertility 92: 361-369.

Goss R. J. 1969. Photoperiodic control of antler cycles in deer: Phase shift and frequency changes. Journal of experimental Zoology 170: 311-324.

Haigh J. C., Cates C., Glover W. F. and Rawlings N. C. 1984. Relationship between seasonal changes in serum testosterone concentrations, scrotal circumference and sperm morphology of male wapiti (Cervus elaphus). Journal of Reproduction and Fertility 70: 413-418.

Hershkovitz P. 1982. Neotropical deer (Cervidae). Part 1. Pudus genus Pudu Grey. Feldiana Zoologica, New Series 11: 43-86.

Hocherau-de Riviers M.-T. and Lincoln G. A. 1978. Seasonal variation in the histology of the testis of the red deer, Cervus elaphus. Journal of Reproduction and Fertility 54: 209-213.

Jaczewski Z. 1954. The effect of altered day leghth on the growth of antlers in the deer (Cervus elaphus L.). Folia Biologica 2: 133-143.

Lincoln G. A. 1971. The seasonal reproductive changes in the red deer stag (Cervus elaphus L.) Journal of Zoology 25: 41-54.

Lincoln G. A. 1985. Seasonal breeding in deer. [In: Biology of deer production. K. Drew and P. Fenessy, eds]. Royal Society of New Zealand, Bulletin 22: 165-179. 
Loudon A. S. I. and Curlewis J. D. 1988. Cycles of antler and testicular growth in an aseasonal tropical deer (Axis axis). Journal of Reproduction and Fertility 83: 729-738.

Mirarchi R. E., Scanlon P. F. and Kirkpatrick R. L. 1977. Annual changes in spermatozoan production and associated organs of white-tailed deer. Journal of Wildlife Management 41: 92-99.

Mirarchi R. E., Howland B. E., Scanlon P. F., Kirkpatrick R. L. and Sanford L. M. 1978. Seasonal variation in plasma LH, FSH, prolactin and testosterone in adult male white-tailed deer. Canadian Journal of Zoology 56: 121-127.

Monfort S. L., Brown J. L., Bush M., Wood T. C., Wemmer C., Vargas A., Williamson L. R., Montali R. J. and Wildt D. E. 1993. Circannual interrelationship among reproductive hormones, gross morphometry, behavior, ejaculate characteristics and testicular histology in Eld's deer stags (Cervus eldi's thamin). Journal Reproduction and Fertility 98: 471-480.

Mourik S. van and Stelmasiak T. 1990. Endocrine mechanisms and antler cycle in rusa deer (Cervus rusa timorensis). [In: Horns, pronghorns and antlers. G. A. Bubenik and A. B. Bubenik, eds]. Springer-Verlag, New York: 413-421.

Reyes E., Guzman R., Angulo A., Hermosilla I. and Conejeros Y. S. 1988. Ciclo de vida y madurez sexual de Pudu puda (Molina) (Mammalia, Cervidae). (Life cycle and sexual maturity of Pudu puda). Boletin de Sociedad de Biologia de Concepcion, Chile 59: 143-150.

Reyes-Toledo E., Munoz P., Recabarren S., Torres P. and Bubenik G. A. 1993. Seasonal variation of LH and testosterone in the smallest deer, the pudu (Pudu puda Molina) and its relationship to the antler cycle. Comparative Biochemistry and Physiology 106: 268-273.

Rolf H. J. and Fischer K. 1990. Serum testosterone (T) and 5-alpha-dihydrotestosterone (DHT) in male fallow deer (Dama dama L.): Seasonality and age dependence. Comparative Biochemistry and Physiology 95A: 445-452.

Schams D. and Barth D. 1982. Annual profiles of reproductive hormones in peripheral plasma of the male roe deer (Capreolus capreolus). Journal of Reproduction and Fertility 66: 463-468.

Sempere A. J. 1990. The annul antler cycle of the european roe deer (Capreolus capreolus) in relation to the antler cycle. [In: Horns, pronhorns and antlers. G. A. Bubenik and A. B. Bubenik, eds]. Springer Verlag, New York: 396-415.

Stieve H. 1949. Anatomisch-biologische Untersuchungen über die Fortfplanzungstätigkeit des europaeischen Rehes (Capreolus capreolus L.). Zeitschrift für mikroskopisch-anatomische Forschung 55: 427-530.

Suzuki M., Kaji K. and Nigi H. 1992. Annual changes of testis size, seminiferous tubules and plasma testosterone concentrations of wild sika deer (Cervus nippon yesoensis Heude, 1884) in Hokkaido. Journal of Veterinary Medicine and Science 54: 551-556.

Wislocki G. B., Aub J. C. and Waldo C. M. 1947. The effect of gonadectomy and the administration of testosterone propionate on the growth of antlers in male and female deer. Endocrinology 40: $202-224$.

Zuckerman S. 1953. The breeding seasons of mammals in captivity. Proceedings of Zoological Society of London 122: 827-950.

Received 16 August 1996, accepted 6 January 1997. 